Part of Journal of Research of the National Bureau of Standards, Volume 17, September 1936

\title{
THE FRENCH SUGAR SCALE
}

\author{
By Frederick Bates and Francis P. Phelps
}

\section{ABSTRACT}

Two different saccharimeter scales are in use today, and although each purports to give the correct percentage of sucrose in a given sample, there is an outstanding difference between the two of approximately 0.1 percent. The industrial importance of the commodity sucrose and its associated products in international trade requires that this difference be eliminated.

A research into the history of the French Sugar Scale and its normal weight discloses the fact that the value of this constant now in official use was originally adopted upon evidence which at the present day would be considered insufficient and that although the two subsequent outstanding experimental redeterminations of this constant gave results somewhat smaller than the official value, those results were considered at the time to be ample confirmation of the then accepted value. A calculation from modern data shows that the French normal weight required to bring the International Sugar Scale and the French Sugar Scale into agreement is exactly that actually obtained by the older French investigators whose work is mentioned above.

Two markedly different saccharimeter scales are in use today, each purporting to give the correct percentage of sucrose in a sample. They are the French Scale and the International Sugar Scale. The former is used largely in France and the French Colonies; the latter is used generally throughout the world. The International Sugar Scale is the official scale of the International Commission for Uniform Methods of Sugar Analysis and was adopted at the eighth session of the Commission in 1932, at Amsterdam. Obviously any saccharimeter scale is, by definition, a basis on which the standardization of the saccharimeter may be brought about. In any consideration of the saccharimeter scale it is essential that there be kept clearly in mind the differentiation between mere definition of the scale and the numerical values of the constants upon which its correctness depends. The confusion which has always existed with regard to saccharimeter scales may be correctly attributed to the inaccurate determination of these constants.

Probably no industrial commodity is so widely utilized in international trade as sucrose and its associated products. Therefore, it is of great importance that there be but one sugar scale, that is, one basis of standardization of saccharimeters in use throughout the world. Such a consummation must ultimately be brought about in view of the importance of the matter to international trade and especially because of the necessity of reporting the results of research workers in unmistakable values. Until this can be done, and under present conditions it is therefore of special importance, insofar as the inherent characteristics of the French and the International Sugar Scales will permit, that the two scales give results that are in agreement within 
the experimental error with which saccharimeter measurements can be made. It is fundamental that tests of a sample of sucrose should show an identical sucrose content regardless of the scale used.

After a number of changes had been made in the normal weight for the French Scale, the value $16.29 \mathrm{~g}$, weighed in air with brass weights, was officially adopted in 1896, and has been the official value ever since. Because of the uncertainty which existed regarding the correctness of the value $16.29 \mathrm{~g}$, two subsequent redeterminations of the value of the normal weight were carried out by French investigators. The reported values were considered "sufficiently close" to the then accepted $16.29 \mathrm{~g}$ normal weight to confirm the correctness of that value. The main purpose of this paper is to direct attention to the fact that had the values for the normal weight actually found by the French investigators been adopted the French Scale and the International Scale would now be in agreement.

It is of interest to recall that the French Sugar Scale was originally based upon the rotation of $1 \mathrm{~mm}$ of quartz to fix the $100^{\circ}$ point. This constant was determined by Broch to be $21^{\circ} 40^{\prime}\left(21.667^{\circ}\right)$ for sodium light. Subsequently by general usage this value was contracted to $21.67^{\circ}$. In converting this value $\left(21^{\circ} 40^{\prime}\right)$ into degrees it is essential, from the standpoint of accuracy and clearness, that the value $21.667^{\circ}$ should be used instead of the rounded value $21.67^{\circ}$, since $0.002^{\circ}$ corresponds to $0.01^{\circ}$, French Sugar Scale. The $100^{\circ}$ point, French Sugar Scale, on circular-scale instruments needs to be defined with a precision of $\pm 0.002^{\circ}$. Instruments were constructed on the above basis, and when it was later found that the rotation for $1 \mathrm{~mm}$ of quartz was somewhat higher, namely, $21.728^{\circ}$, the previous value, $21.67^{\circ}$, was retained in order to avoid confusion of scales. This procedure necessitated the abandonment of the original definition of the $100^{\circ}$ point for the French Scale.

The normal weight may therefore be defined as that weight of sucrose which, when made up and polarized under standard conditions, gives the same reading on a quartz compensating instrument as a quartz plate having an absolute rotation of $21.67^{\circ}$ for $\lambda=5892.5 \mathrm{~A}$.

The normal weight, the specific rotation $[\alpha]_{\mathrm{p}}^{20}$, and the observed rotation $\alpha^{20}{ }_{\mathrm{p}}$ are connected by the equation

$$
[\alpha]_{\mathrm{D}}^{20}=\frac{100 \alpha_{\mathrm{D}}^{20}}{C_{n} \times l} \text { or } C_{n}=\frac{100 \alpha_{\mathrm{D}}^{20}}{[\alpha]_{\mathrm{D}}^{20} \times l},
$$

where $C_{n}$ is the concentration, or normal weight per $100 \mathrm{ml}$ of solution, and $l=$ length, in decimeters. It is, therefore, obvious that if the observed rotation is a constant $\left(21.67^{\circ}\right)$ the exact normal weight, $C_{n}$, will depend upon what value is accepted as the correct specific rotation. After a number of changes in the normal weight the value $16.29 \mathrm{~g}$, weighed in air with brass weights, was officially adopted in 1896 and, as above stated, has remained the official value.

As the years have passed manufacturers of saccharimeters have improved the quality of their product until, although still based upon the same fundamental principles, the precision attainable with the modern saccharimeter has been materially increased. The best present-day saccharimeters, under optimum and carefully controlled conditions, permit a precision approaching one or two hundreths of a sugar degree. 
Since it is axiomatic that a standard should be specified with an accuracy at least as great as can be attained with the instruments in connection with which it is to be used, it would seem that the value of the normal weight, $16.29 \mathrm{~g}$, although probably amply good at the time it was adopted, is now in need of modification.

\section{Since}

$16.29 \mathrm{~g}$ corresponds to $100^{\circ}$ (French Sugar Scale),

$\pm 0.01 \mathrm{~g}$ corresponds to $\pm 0.06^{\circ}$ (French Sugar Scale), and

$\pm 0.002 \mathrm{~g}$ corresponds to $\pm 0.012^{\circ}$ (French Sugar Scale).

Therefore, in order to have the precision of the normal weight commensurate with that of the best modern saccharimeters, it should be specified with an accuracy of about $\pm 0.002 \mathrm{~g}$. Obviously this means giving three figures after the decimal instead of rounding off to two figures. In considering this correction it should be noted that the value $16.29 \mathrm{~g}$ was calculated by Sidersky in $1885,{ }^{1}$ and that all subsequent experimenters have obtained values slightly lower than $16.29 \mathrm{~g}$. In that year Sidersky called attention to an error in the then official normal weight of $16.19 \mathrm{~g}$, and was criticized for questioning the correctness of the official normal weight. ${ }^{2}$ Nevertheless, Sidersky had the courage of his convictions and 11 years later, in 1896, his value was made the official value. This value $(16.29 \mathrm{~g})$ was based upon two considerations: (1) a calculation of the normal weight using 'Tollens' value ${ }^{3} 66.5^{\circ}$ for the specific rotation of sucrose, whereby he obtained the value $16.295 \mathrm{~g}$, and (2) the direct comparison of a Schmidt \& Haensch and a Laurent saccharimeter by means of a quartz plate, which he read in both instruments. He assumed that the Schmidt \& Haensch instrument was correct, since it was supposed to be directly calibrated by means of pure sucrose, and calculated the weight which would have to be used with the Laurent instrument to give the correct percentage of sugar. He found for this value $16.30 \mathrm{~g}$, which confirmed his calculated value $16.295 \mathrm{~g}$. It was not known at that time, as it is now that the Schmidt \& Haensch instruments of those days were in error by about 0.2 percent, the $100^{\circ}$ point then corresponding to an absolute rotation of $34.68^{\circ}$ instead of $34.620^{\circ}$, as at present. Had this error been known at that time, Sidersky's experiment would have yielded a result of 0.2 percent lower, or $16.27 \mathrm{~g}$. Also, as mentioned above, all subsequent determinations of the normal weight have yielded results slightly lower than $16.29 \mathrm{~g}$.

Following the action of the $11^{\mathrm{me}}$ Congrès International de Chimie Appliquée (Paris, 1896) in adopting $16.29 \mathrm{~g}$ as the official normal weight for the French Scale, a commission was appointed for the revision of the saccharimetric normal weight. This commission decided that further experimental work was required in order to establish the normal weight on a firm foundation. This work was undertaken by Mascart and Benard at the Collège de France and also by $\mathrm{H}$. Pellet at the Sorbonne.

As the result of these experiments the correctness of the value $16.29 \mathrm{~g}$ was considered to be amply confirmed. However, Mascart and Benard ${ }^{4}$ gave 66.54 as the specific rotation of sucrose, and $16.284 \mathrm{~g}$ weighed in vacuo as the normal weight. Through an error in converting this weight in vacuo to weight in air with brass weights they

1 Bul. assn. chim. sucr. dist. 3-4, 255 (1835-86)

2 Bul. assn. chim. sucr. dist. 50, 355 (1933)

3 See footnote 1 .

Ann. chim. phys. 17, 125 (1899). 
arrived at the value $16.29 \mathrm{~g}$, confirming Sidersky's calculation. If this error is eliminated Mascart and Benard's value becomes $16.27 \mathrm{~g}$.

Also Pellet ${ }^{5}$ gave $[\alpha]_{D}^{20}=66.536^{\circ}$, and $16.285 \mathrm{~g}$ in vacuo for the normal weight. The latter corresponds to 16.27 weighed in air with brass weights.

In 1933, 38 years after his original calculation, Sidersky ${ }^{6}$ accepts the specific rotation of $66.54^{\circ}$ given by Schönrock ${ }^{7}$ as the best average value and again calculates the normal weight and finds the value to be $16.282 \mathrm{~g}$. This he says differs by only a negligible amount from $16.29 \mathrm{~g}$. Sidersky appears to have overlooked the fact that the specific rotation calculated from Schönrock's formula which he accepts is that based upon weights in vacuo, and hence that the normal weight which he obtains is the normal weight in vacuo. Corrected to weighings in air with brass weights his figure becomes $16.272 \mathrm{~g}$. If $21.667^{\circ}$ be used, instead of $21.67^{\circ}$ which Sidersky used, this figure is still further reduced to $16.270 \mathrm{~g}$. The difference between this value and $16.29 \mathrm{~g}$ is not negligible, corresponding as it does to about $0.1^{\circ}$, French Sugar Scale.

At the eighth session of the International Commission for Uniform Methods of Sugar Analysis, 1932, the Commission in fixing the constants for the International Sugar Scale adopted the following: ${ }^{8}$

Normal quartz plate $=100^{\circ} \mathrm{S}=34.620 \pm 0.002^{\circ}(\lambda=5892.5 \mathrm{~A})$ at $20^{\circ} \mathrm{C}$. Thus the working standard used to fix the $100^{\circ} \mathrm{S}$ point is a quartz plate of such thickness that its rotation for sodium light is $34.620^{\circ}$. This standard corresponds to the procedure in the French Sugar Scale wherein the $100^{\circ}$ point is determined by the quartz plate whose thickness is such that it has a rotation of $21^{\circ} 40^{\prime}\left(21.667^{\circ}\right)$ for sodium light. For practical purposes the $100^{\circ}$ point in both cases is fixed by an absolute rotation. It is thus clear that in establishing both scales actual physical measurements must be made of the weights and of the rotations. It therefore makes no difference in the final results whether the weight be considered fundamental and the rotation consequential or whether the rotation be considered fundamental and the weight consequential. Both procedures if correctly carried out lead to the same result, namely, a relation between weight and rotation. In this connection, however, it should be pointed out that for the fundamental purpose of fixing the $100^{\circ} \mathrm{S}$ point the physical procedure indicated by the International Scale is to be preferred, among other reasons, because it gives a more open scale and accurate polarizations are easier to obtain.

A direct comparision of the two scales is therefore possible through their respective normal weights and will show how closely they are in agreement; i. e., whether the two scales actually indicate the same sugar content in a given sample.

If the effect of change in specific rotation with change in concentration is for the moment neglected the two normal weights should be in proportion to the rotations corresponding to the respective $100^{\circ}$ points if the scales are equivalent. Hence, given the two $100^{\circ}$ points and one of the normal weights the other may be calculated by direct proportion. Thus

$$
\frac{34.620^{\circ}}{21.667^{\circ}}=\frac{26.000 \mathrm{~g}}{C_{n}} \text { in } \text { air }=\frac{26.0159 \mathrm{~g}}{C_{n}} \text { in vacuo. }
$$

5 Ann. chim. phys. 23, 289 (1901).

6 See footnote 2.

7 Geiger's Handbuch der Physik 19, 705-776 (1928).

8 Report of the Proceedings of the Eighth Session of the International Commission for Uniform Methods of Sugar Analysis, Subject 1 (d), Int. Sugar J. 35, 17, 62 (1933). 
Solving, the normal weight, $C_{n}$, becomes $16.272 \mathrm{~g}$ in air or $16.282 \mathrm{~g}$ in vacuo. This is the value of the French normal weight required to make the two scales equivalent when the change in specific rotation with concentration is neglected.

From Schönrock's formula the change in specific rotation from $26 \mathrm{~g}$ to $16 \mathrm{~g}$ amounts to 12 parts in 66,540 , corresponding to a decrease in the $16 \mathrm{~g}$ normal weight of about 3 parts in 16,000 , thus making the required French normal weight $16.269 \mathrm{~g}$ in air and $16.279 \mathrm{~g}$ in vacuo for equivalence between the scales.

It is evident from the above that the French normal weight of $16.269 \mathrm{~g}$ necessary to bring the French Scale and the scale of the International Commission for Uniform Methods of Sugar Analysis into equivalence exactly equals that calculated by Sidersky, namely, $16.270 \mathrm{~g}$, after due attention is paid to the obviously necessary correction for buoyancy of the air and the $100^{\circ} \mathrm{F}$. S. point rotation taken as $21.667^{\circ}$, instead of $21.67^{\circ}$.

Since the $100^{\circ}$ point of the French Scale is fixed by definition as a rotation of $21^{\circ} 40^{\prime}=21.667^{\circ}$, it is advisable to use this value to replace the less accurate value of $21.67^{\circ}$ now used. When this change also is made the required normal weight is $16.269 \mathrm{~g}$. Therefore, paralleling the definition of the International Sugar Scale, the following statement would hold for the French Sugar Scale:

(1) Normal quartz plate $=100^{\circ}$ F.S. $=21.667 \pm 0.002^{\circ}(\lambda=5892.5 \mathrm{~A})$ at $20^{\circ} \mathrm{C}$.

(2) The graduation of the saccharimeter shall be made at $20^{\circ} \mathrm{C}$. $16.269 \pm 0.002 \mathrm{~g}$ of sucrose dissolved in water, and the volume made up to $100 \mathrm{ml}$, all weighings to be made in air with brass weights, the completion of the volume and the polarization to be made at $20^{\circ} \mathrm{C}$ on an instrument graduated at $20^{\circ} \mathrm{C}$, gives a reading of $100^{\circ} \mathrm{F}$. S.

From a consideration of the foregoing it is apparent that many of the difficulties and uncertainties which have been attributed to the French Scale never had an actual existence. They have arisen through an error in adopting a normal weight which the experimental evidence did not fully justify. It should be a simple procedure to eliminate them. It is, therefore, suggested that the value $16.269 \pm$ $0.002 \mathrm{~g}$ weighed in air with brass weights, be adopted as the official normal weight for the French Saccharimeter Scale. When this is done the present official normal weight of $16.29 \mathrm{~g}$ will have been discarded. Should this be done not only will the International Sugar Scale and the French Sugar Scale be brought into exact agreement but there will result a long-overdue recognition of the accuracy of the experimental work of those French investigators whose work was interpreted as providing a value of $16.29 \mathrm{~g}$ for the normal weight. It is a fortuitous circumstance that brings the two scales into complete correspondence, and it is worthy of note that these investigators, with the limited facilities available at the early date at which the work was carried out, obtained values for the specific rotation and the normal weight of sucrose identical with those obtained by the use of modern instruments and methods. The adoption of the normal weight $16.269 \mathrm{~g}$ as the official normal weight for the French Saccharimeter Scale would be an important development of great benefit to the sugar industry of the world.

Washington, July 3, 1936. 